\title{
Selective Substituent Transfer from Mixed Zinc Reagents in Ni-Catalyzed Anhydride Alkylation
}

\author{
Jeffrey B. Johnson, Robert T. Yu, Paul Fink, Eric A. Bercot and Tomislav Rovis ${ }^{*}$ \\ Department of Chemistry, Colorado State University \\ Fort Collins, CO 80523
}

\section{Supporting Information}

General Methods. All reactions were carried out under an atmosphere of argon in ovendried glassware with magnetic stirring. Tetrahydrofuran (THF) was purged with argon and passed through two columns of neutral alumina. Anhydrides 3, 4 and 5, $\mathrm{Et}_{2} \mathrm{Zn}$, $i \operatorname{Pr}_{2} \mathrm{Zn}$, and [(1-ethoxycyclopropyl)oxy]trimethylsilane were obtained from Aldrich Chemical Co. and utilized without further purification. Anhydride 6 was prepared by cyclization of the corresponding commercially available diacid. ${ }^{1} \mathrm{Ni}(\mathrm{COD})_{2}$, diphenylphosphinoethane (dppe), bipyridine (bipy), and $\mathrm{Ph}_{2} \mathrm{Zn}$ were purchased from Strem Chemical, Inc. and used without further purification. $i$ PrPHOX and pyphos were prepared according to literature procedure. ${ }^{2,3} \mathrm{Zn}\left(\mathrm{CH}_{2} \mathrm{CH}_{2} \mathrm{CO}_{2} \mathrm{Et}\right)_{2}$ and $\mathrm{Zn}\left(\mathrm{CH}_{2} \mathrm{TMS}\right)_{2}$ were also prepared according to literature procedure. ${ }^{4,5}$ All products generated in this study have been previously described, ${ }^{1,6}$ with the exception of 6-(4-Methoxybenzoyl)cyclohex-3-enecarboxylic acid (see below). ${ }^{1} \mathrm{H}$ and ${ }^{13} \mathrm{C}$ NMR spectra were obtained on a Varian $300 \mathrm{MHz}$ spectrometer at ambient temperature unless otherwise noted. Analytical high performance liquid chromatography (HPLC) was performed on an Agilent 1100 series HPLC using Chiracel chiral columns.

Preparation of diorganozinc nucleophile in situ will be illustrated with a specific example. A solution of 3,4,5-trimethoxy-1-bromobenzene $(632 \mathrm{mg}, 2.56 \mathrm{mmol}$ in 2.4 $\mathrm{mL}$ THF was cooled to $-78{ }^{\circ} \mathrm{C}$. To this solution was added a solution of $n \mathrm{BuLi}$ in hexanes (1.56 M solution, $1.64 \mathrm{~mL}, 2.56 \mathrm{mmol})$. After this mixture was stirred for 30 minutes, a solution of $\mathrm{ZnCl}_{2}$ (174.5 mg, $1.28 \mathrm{mmol}$ in $1.5 \mathrm{~mL}$ THF) was added, and the reaction mixture was allowed to warm to room temperature and stirred for 90 minutes prior to further use. This procedure provides $5.5 \mathrm{~mL}$ of a $0.23 \mathrm{M}$ solution of the diarylzinc reagent. 
General procedure for alkylation using mixed zinc reagents will be illustrated with a specific example. In a $10 \mathrm{~mL}$ round bottom flask, $1 \mathrm{~mL}$ of a solution of diphenyl zinc (prepared according to above procedure, $0.23 \mathrm{M}$ in THF) was combined with an equimolar amount of $\mathrm{Et}_{2} \mathrm{Zn}(24 \mu \mathrm{L}, 0.23 \mathrm{mmol})$. After stirring for 30 minutes, this solution was added to a $1 \mathrm{~mL}$ catalyst solution $\left[\mathrm{Ni}(\mathrm{COD})_{2}(3.0 \mathrm{mg}, 0.011 \mathrm{mmol})\right.$, bipy $(2.1 \mathrm{mg}, 0.013 \mathrm{mmol})$ and styrene $(3 \mu \mathrm{L}, 0.026 \mathrm{mmol})]$ in THF in a second $10 \mathrm{~mL}$ round bottom flask. After cooling to $0{ }^{\circ} \mathrm{C}$, a solution of 2,3-dimethylsuccinic anhydride (29.5 $\mathrm{mg}, 0.32 \mathrm{mmol}$ in $0.5 \mathrm{~mL}$ of THF) was added.

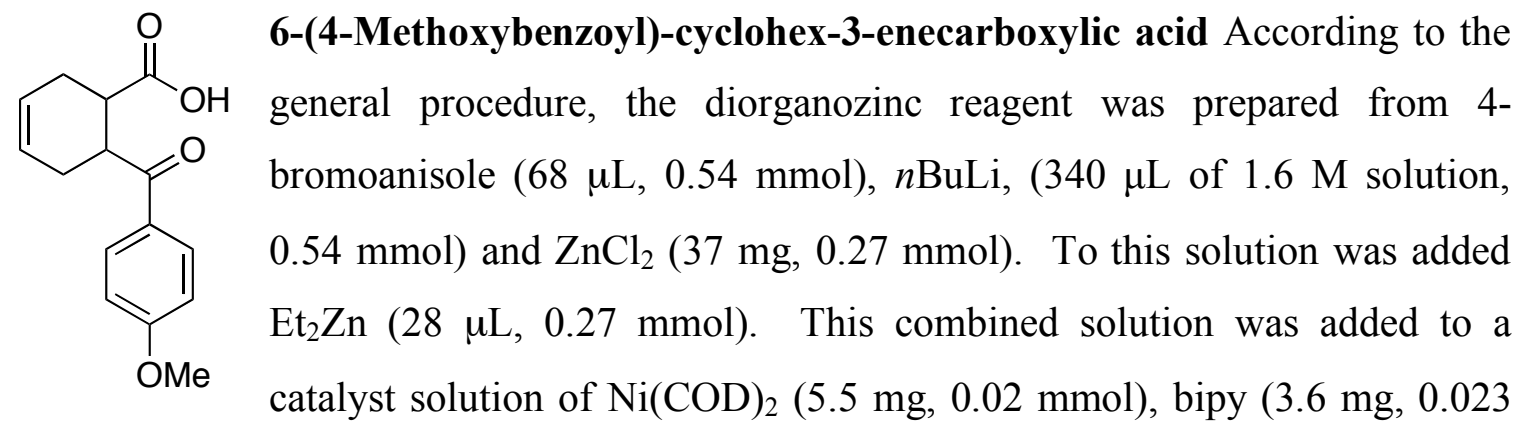
mmol) and styrene $(4.5 \mu \mathrm{L}, 0.039 \mathrm{mmol})$. The solution was cooled to $0{ }^{\circ} \mathrm{C}$ and cis1,2,3,6-tetrahydrophtahlic anhydride 3 (60 $\mathrm{mg}, 0.39 \mathrm{mmol})$ was added and stirred for 16 h. ${ }^{1} \mathrm{H}$ NMR (300 MHz, $\left.\mathrm{CDCl}_{3}\right) \delta$ 2.35-2.59 (m, 3H), 2.75-2.88 (m, 1H), 2.94-3.07 (ddd, $J=6.3,3.9,3.3,1 \mathrm{H}), 3.86(\mathrm{~s}, 3 \mathrm{H}), 3.94(\mathrm{ddd}, J=6.0,3.6,3.3,1 \mathrm{H}), 5.57-5.70(\mathrm{~m}, 1 \mathrm{H})$, 5.71-5.80, 6.93 (d, $J=8.8 \mathrm{~Hz}, 2 \mathrm{H}), 7.87$ (d, $J=8.8 \mathrm{~Hz}, 2 \mathrm{H}) .{ }^{13} \mathrm{C} \mathrm{NMR}\left(75 \mathrm{MHz}, \mathrm{CDCl}_{3}\right)$ $\delta 200.6,179.1,163.5,130.9,129.0,126.0 .124 .1,114.0,55.8,41.6,39.9,27.5,26.5$. HRMS $\left[\mathrm{C}_{15} \mathrm{H}_{17} \mathrm{O}_{4}\right]^{+}$calc 261.1136. Found 261.1127. 
6-(4-Methoxybenzoyl)-cyclohex-3-enecarboxylic acid

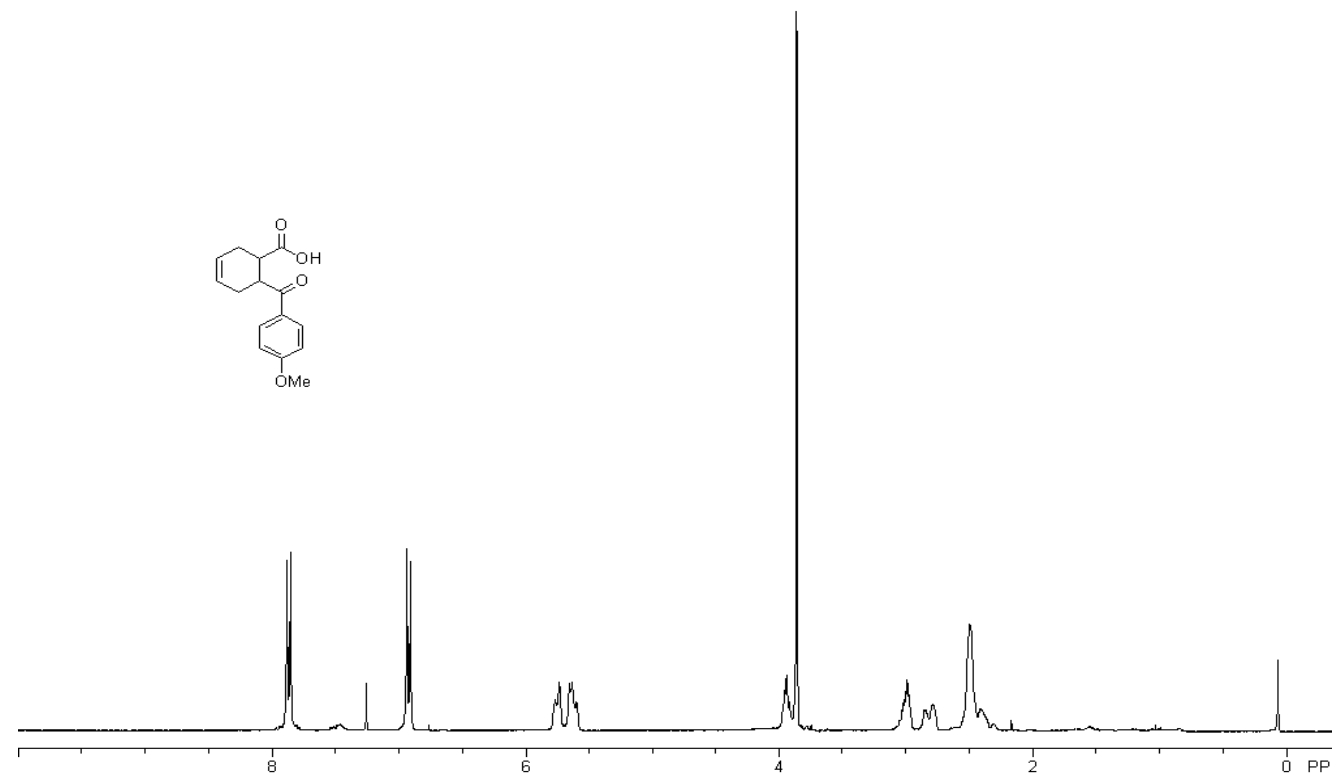

6-(4-Methoxybenzoyl)-cyclohex-3-enecarboxylic acid
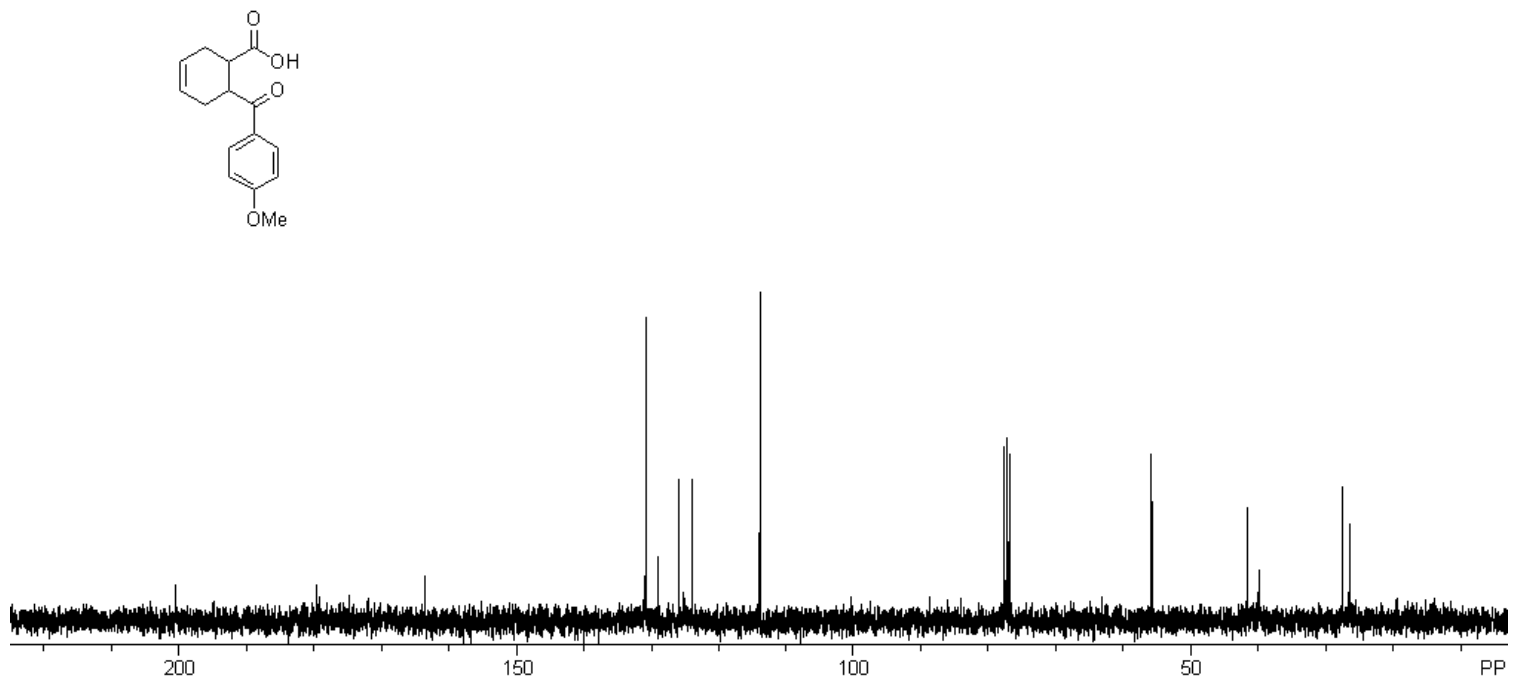
${ }^{1}$ Bercot, E. A.; Rovis, T. J. Am. Chem. Soc. 2005, 127, 247.

${ }^{2}$ Allen, J. V. ; Dawson, G. J. ; Frost, C. G.; Williams, J. M. J. Tetrahedron, 1994, 50, 799.

${ }^{3}$ Toto, S. D.; Doi, J. T. J. Org. Chem. 1987, 32, 4999.

${ }^{4}$ Zhang, Y.; Rovis, T. J. Am. Chem. Soc. 2004, 126, 15964.

${ }^{5}$ Westerhausen, M.; Rademacher, B.; Poll, W. J. Organomet. Chem. 1991, 427, 175.

${ }^{6}$ Bercot, E. A.; Rovis, T. J. Am. Chem. Soc. 2002, 124, 174. 